\title{
FORMAÇÃO DOCENTE E INCLUSÃO DE ALUNOS COM TEA EM CLASSES REGULARES
}

Andrea Neves da Silva ${ }^{1}$

\section{RESUMO}

Tradicionalmente o conceito de formação continuada para professores ocorre com o intuito de haver um renovar na prática pedagógica em busca de preencher lacunas e adaptar possíveis ajustes ao contexto docentes x "práxis pedagógica" onde se faz necessário refletir, reorganizar e reinventar "o ciclo" que existe no processo educacional que deve ser contínuo, progressivo; mas também revisado e readaptado/reajustado quando constatado que é insuficiente para cumprir com as metas propostas pelas unidades escolares; principalmente sobre o processo de inclusão dos autistas. Desse modo, o presente artigo tem a meta de detalhar a formação docente no Brasil voltada para inclusão de alunos com TEA em classes regulares. Espera-se, com este estudo, contribuir para a comunidade científica a fim de favorecer a ocorrência de mais iniciativas formativas.

Palavras-chave: TEA; Formação Docente; Inclusão; Classes Regulares.

\section{ABSTRACT}

Traditionally, the concept of continuing education for teachers occurs with the aim of renewing pedagogical practice in order to fill gaps and adapt possible adjustments to the teaching context $x$ "pedagogical praxis" where it is necessary to reflect, reorganize and reinvent "the cycle" that exists in the educational process that must be continuous, progressive; but also revised and readjusted/readjusted when found to be insufficient to meet the goals proposed by the school units; mainly on the process of inclusion of autistic people. Thus, this article aims to detail the teacher education in Brazil aimed at the inclusion of students with TEA in regular classes. It is expected, with this study, to contribute to the scientific community in order to favor the occurrence of more formative initiatives.

Keywords: TEA; Teacher Training; Inclusion; Regular Classes.

\section{RESUMEN}

Tradicionalmente, el concepto de educación continua para docentes se dá con el objetivo de renovar la práctica pedagógica con el fin de llenar vacíos y adaptar posibles ajustes al contexto docente x "praxis pedagógica" donde es necesario reflexionar, reorganizar y reinventar "el ciclo" que existe en el proceso educativo que debe ser continuo, progresivo; pero también revisado y reajustado/reajustado cuando se consideró que era insuficiente para cumplir con los objetivos propuestos por las unidades escolares; principalmente en el proceso de inclusión de las personas autistas. Así, este artículo tiene como objetivo detallar la formación docente en Brasil dirigida a

${ }^{1}$ Possui graduação em Pedagogia pelo Centro Universitário Moacyr Sreder Bastos (2006) e especialização em Gestão Escolar: Orientação e Supervisão na Área de Educação pelo Centro Universitário Barão de Mauá (2014). Atualmente, é Professor II da Prefeitura da Cidade do Rio de Janeiro. 
la inclusión de los estudiantes con TEA en las clases regulares. Se espera, con este estudio, contribuir a la comunidad científica para favorecer la ocurrencia de iniciativas más formativas.

Palabras clave: TEA; Formación del Profesorado; Inclusión; Clases Regulares.

\section{INTRODUÇÃO}

Existem diversos termos empregados para formação continuada de docentes: capacitação; qualificação; aperfeiçoamento; reciclagem; atualização; formação continuada; formação; entre diversos outros conceitos.

Normalmente, são promovidos pelas Secretarias Estaduais ou Municipais de Educação, onde os docentes estão vinculados ou por outras entidades interessadas na área; inclusive, muitas formações estão sendo ofertadas nas próprias unidades escolares ou nos Centros Educacionais específicos das Secretarias de Educação; tornando o processo de capacitação mais ajustado ao cronograma dos docentes e sem gerar custos a estes profissionais.

Sabe-se, também, que qualquer profissional pode buscar aperfeiçoar-se através de diversos cursos e modalidades televisionadas, inclusive na internet; enfim, no contexto educacional contemporâneo, há infinitos recursos para que haja o aprimoramento profissional: palestras e aulas excelentes que podem ser acessadas a qualquer momento.

Com esse pensamento, o presente artigo objetiva detalhar a formação docente no Brasil voltada para inclusão de alunos com TEA em classes regulares. Assim, entende-se que o profissional que porta a consciência de que deve sempre se aperfeiçoar é um especialista de grande excelência e com certeza estará aberto ao diálogo, à inclusão e às mudanças; principalmente a partir da interação e conhecimentos adquiridos na formação continuada.

\section{FORMAÇÃO CONTINUADA}

Observa-se que atitude e vontade de se adequar às necessidades para aprimorar a prática pedagógica inclusiva são indispensáveis. E, também, a comunicação é muito importante, pois através dela transmite-se desejos, pensamentos e trocas de informações em equipe; é indispensável que seja clara e

\section{CONMRGÊNAASTEĆRCASDOMNDOCONIEMPORÂNED}


precisa, principalmente quando se trata de profissionais que trabalham continuamente com educandos especiais.

A inquietação, a ousadia e a proatividade, em conjunto com a motivação e flexibilidade, também fazem parte do perfil de um empreendedor excepcional, posto que ele não se cansa de observar, está sempre procurando novas oportunidades, precisa ter suas necessidades realizadas e ser capaz de se adaptar às mais distintas situações. Costa (2012) defende:

\begin{abstract}
[...] implementação da educação inclusiva com planejamento para suas diversas etapas, desde a formação dos professores até a organização pedagógica da escola, para que se constitua em um processo de enfrentamento e de encaminhamento das propostas, dos programas e de adoção de princípios pedagógicos entendidos e acolhidos pelos professores, envolvidos diretamente no ensino e na avaliação da aprendizagem dos alunos, com respeito às minorias historicamente excluídas das instâncias sociais (COSTA, 2012, p. 145).
\end{abstract}

Interessantemente, o pedagogo Candau (1999), intitula à formação continuada o termo reciclagem; o que o difere de outros estudiosos que entendem a palavra "reciclar" como um termo específico da indústria e, por isso, aplicado somente à reutilização de materiais recicláveis, não coerente com o processo de formação continuada dos profissionais da educação enquanto sujeitos do fazer.

É notória a necessidade de reciclagens em prol de mudanças inclusivas relevantes e contextualizadas com a realidade social do aluno; incluindo novos programas e novas tecnologias do mundo globalizado e imediatista para suprir as diversas lacunas que surgem constantemente em sala de aula quando os docentes não conseguem acompanhar e suprir as necessidades dos alunos.

A este processo de formação, deve-se somar o estreitamento da relação do docente com os pais/responsáveis dos educandos. Ao professor, sobeja a atribuição de estabelecer um diálogo capaz de alertá-los para as nuances de seus filhos, abrangendo tanto aqueles alunos com dificuldades de aprendizado, quanto àqueles que podem estar acometidos por algum distúrbio.

\title{
RELAÇÃO PROFESSOR X ALUNO COM TEA
}

Realmente o professor precisa saber lidar com cada criança, com cada situação em particular. Os professores além de serem formadores de opinião

\section{CONGRGÂNAASTEÓRCASDOMNDOCONIEMPORÂNEO}


passam conhecimento e servem de referência para ajudá-los na construção do saber; precisam ser atenciosos e afetivos. Somente após a conquista do aluno é que se consegue passar confiança e qualquer trabalho poderá ser feito.

Alves (2001) menciona que: "todo jardim começa com uma história de amor, antes que qualquer árvore seja plantada ou um lago construído é preciso que eles tenham nascido dentro da alma"; dessa forma, compara o professor a um jardineiro que cuida de seu jardim cheio de alunos. Entende-se que no universo escolar é imprescindível que haja sintonia entre professor e aluno.

Ainda que a tarefa a ser executada seja simples, poderá existir dificuldades, mas será um avanço para aqueles que estavam na inércia ou desmotivados com medo de tentarem realizar algo por vergonha, ou terem sido estigmatizados por alguém. É bem verdade que a própria sociedade é estigmatizante por natureza, pois nenhum pai quer um filho com problemas especiais ou qualquer limitação. Conforme consta no site da Unicef.org sobre a Conferência de Jomtien (1990):

\begin{abstract}
A aprendizagem não ocorre em situação de isolamento. Portanto, as sociedades devem garantir a todos os educandos assistência em nutrição, cuidados médicos e o apoio físico e emocional essencial para que participem ativamente de sua própria educação e dela se beneficiem. (...) A educação das crianças e a de seus pais ou responsáveis respaldam-se mutuamente, e esta interação deve ser usada para criar, em benefício de todos os ambientes de aprendizagem onde haja calor humano e vibração (DECLARAÇÃO MUNDIAL SOBRE EDUCAÇÃO PARA TODOS, 1990).
\end{abstract}

Conforme mencionado acima, todos precisam respeitar as diferenças independentemente de quais sejam. Os profissionais de todas as disciplinas devem trabalhar com projetos, atividades escolares e extraescolares capazes de interferir qualitativamente na vida de cada indivíduo; tornando a escola mais aprazível e acolhedora, pois para o educando o ambiente escolar é um lugar que ficará registrado em sua mente de acordo com suas atuações durante o processo de ensino-aprendizagem. Todos os indivíduos registram o que possui sentido e/ou alguma relação afetiva.

Sendo assim, o professor deve deixar o ambiente em sintonia, envolvendo o educando para que ele consiga se sentir num "mundo diferente"; desafiador, mas sem perder sua identidade; lugar inclusivo acolhedor com grandes desafios e descobertas.

\title{
CONMRRGÁNAASTEÓRICASDOMNDOCONIEMPORÂNEO
}




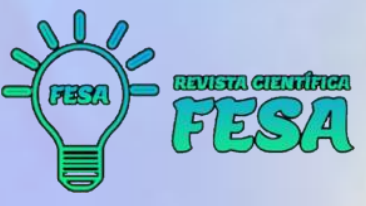

É muito gratificante para o professor poder interagir com a diversidade e presenciar cada nova descoberta, avanço; enfim, caminhar junto com os educandos especiais em prol de grandes conquistas por mais simples que sejam. Consta na Lei de Diretrizes e Bases da Educação o apoio aos profissionais para que esta interação ocorra: "Haverá, quando necessário, serviços de apoio especializado, na escola regular de ensino" (BRASIL, 1966, p. 41).

No ambiente escolar, para que o professor possa atuar da melhor maneira possível no processo educativo dos educandos especiais, ele deve observá-los em todas as suas particularidades para perceber os indicadores a serem registrados. É fato que determinados comportamentos como a motivação para o trabalho escolar, o ritmo de trabalho, a constância no esforço, a atitude diante dos erros e dificuldades, a capacidade de concentração, e desenvoltura no trabalho proposto pelo professor, podem ser traços que indicam algum distúrbio / transtorno no aprendizado.

A partir destas observações comportamentais, do diálogo com os responsáveis e da avaliação de uma equipe psicopedagógico escolar, será possível realizar encaminhamentos para um tratamento ambulatorial especializado formado por uma equipe multidisciplinar capaz de diagnosticar com clareza cada aluno.

No limiar do processo inclusivo, a união entre a equipe educacional sob orientação psicopedagógica, a equipe médica multidisciplinar e os familiares atentos e conscientes, será o fator inicial para um ciclo de aprendizado pleno e para a completa inserção de todo aluno na sociedade como indivíduo democraticamente participativo.

Nesta perspectiva de um ensino democrático, o qual inclui a horizontalidade de abordagens e de acompanhamento dos educandos é necessário que haja uma preocupação em atender às necessidades do aluno sob o ponto de vista de uma educação institucional e social. Incluí-lo em diversas atividades pensadas e adaptadas para sua participação, torna-o indivíduo com aspirações de igualdade e cidadania, consciente de suas dificuldades, porém atento aos seus sucessos cotidianos.

Sabe-se que, antigamente, a sociedade costumava atribuir ao educando especial toda a culpa por seu fracasso escolar, mas isso mudou muito, pois entende-se que muitos são os fatores que interferem no aprendizado. Devido a 
esta situação, é necessário dar atenção, paciência, carinho e despertar o interesse pelo aprendizado, pois estes educandos devem se sentir motivados para executarem qualquer tarefa e participarem ativamente dos desafios, erros e acertos.

A motivação é importante para que haja autoestima e aumente a vontade de aprender. Segundo Chalita (2001):

O grande pilar da educação é, sem dúvida, a habilidade emocional. Não é possível desenvolver a habilidade cognitiva e social sem que a emoção seja trabalhada. Trabalhar a emoção requer paciência; tratase de um processo continuado porque as coisas não mudam de uma hora para outra (CHALITA, 2001, p. 232).

Neste contexto, cada pessoa é diferente e devido a isso possui o tempo de adquirir conhecimento diferenciado e é necessário que as diferenças sirvam de estímulo para novos aprendizados e não como um obstáculo. Isso supõe mudanças profundas na escola. Supõe mudar, entre outras coisas, a abordagem da atividade que o docente se propões a ministrar. Ela deve ser capaz de conseguir que todos trabalhem e aprendam a partir de suas próprias possibilidades; aptidões.

Sendo assim, a escola enquanto espaço social, de afetividade e de valores éticos e morais deve estar aberta às mudanças para que haja bons resultados e os alunos avancem na aquisição da troca de conhecimentos extramuros. Para isto, é indispensável que o professor transmita um ensinamento mais diversificado, mais interessante e menos exaustivo; desta maneira o educando conseguirá progredir e assimilar conhecimentos relevantes.

\section{RELAÇÃO PROFESSOR X PROFISSIONAIS DE APOIO PARA A INCLUSÃO DO ALUNO COM TEA (DIREÇÃO, COORDENAÇÃO, MEDIADORES E OU- TROS PROFISSIONAIS)}

Entende-se que a educação contemporânea necessita de um olhar mais humano e inclusivo, e para que isso ocorra, é fundamental que pessoas capacitadas para a função de gestor escolar também estejam aptas a assumirem este compromisso. Sabe-se que os professores possuem papel importante na 


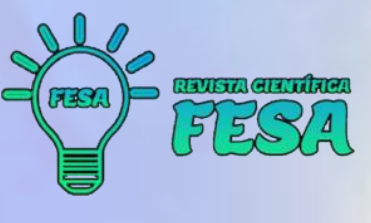

consolidação desta gestão educacional. Eles contribuem com ideias, necessidades e impressões sobre questões diversas suscitadas no cotidiano escolar.

Entende-se que a gestão escolar tem como objetivos a máxima convergência de forças e de interesses em prol do bem da escola. Nesse sentido, a boa relação desenvolvida com toda a equipe dentro do espaço escolar é primordial. Propor um ambiente participativo deixando de lado uma expectativa burocrática e centralizadora ajudará a promover uma estrutura de democracia, inclusão e participação, que é o real objetivo.

Luck (2010), ao defender a participação nos processos decisórios escolares, elenca os benefícios da gestão democrática. Para a autora (op. cit.), espaços com essa característica tornam-se benéficos porque melhoram a qualidade pedagógica; institui currículos mais densos e concretos, atuais e reais; aumentam o profissionalismo docente; afastam uma postura de isolamento por parte dos diretores e dos professores; motivam o apoio pedagógico e comunitário; possibilitando desenvolver projetos multidisciplinares.

Todos esses benefícios enumerados pela autora (op. cit.) são possíveis a partir de uma postura diretiva que propõe diálogo e ampla participação. Se não houver garantias desse tipo de organização, dificilmente será possível unir os anseios e as experiências prática das diversas áreas essenciais à educação docentes, profissionais de apoio, discentes e responsáveis.

Quando os docentes inseridos no ambiente educacional se predispõem a compreender as ferramentas de inclusão, conseguem transmitir as informações aos demais profissionais da equipe escolar, e assim, possibilitam multiplicar as estratégias para que seus alunos sejam atendidos com o devido respeito, consideração e inclusão.

Ademais, o docente, ao lado do psicopedagogo, deve estabelecer metas para pôr em prática um plano de intervenção e de inclusão, de modo gradual e contínuo, adaptado a cada grau de dificuldade distinto. Somente deste modo, através de um acompanhamento orientado, é possível conceber o desenvolvimento do aluno autista sem que ele passe por grandes traumas.

Constata-se que somente com a união de toda a equipe escolar será capaz de efetivamente haver transformações qualitativas e motivacionais. É indispensável que toda a equipe assuma a responsabilidade em relação a sua prática docente e criem estratégias para enfrentar novos desafios no universo escolar. 
$\begin{array}{ll}\text { Ago. } 2021 & \text { v. } 1, \text { n. 7, 03-12 } \\ \text { ISSN: } 2676-0428\end{array}$

E, conforme Vasconcellos (2003) "o professor necessita de conhecimentos e práticas que ultrapassem o campo de suas especialidades."

Somente com uma postura investigativa e motivadora, os professores, equipe diretiva e demais profissionais da unidade escolar conseguirão aguçar a curiosidade dos alunos, despertar as múltiplas inteligências e incentivá-los a enfrentar as adversidades da vida tendo a certeza de que serão capazes de obter sucesso.

Entende-se que as dificuldades de aprendizagem sempre existiram, mas a escola, juntamente com sua equipe pedagógica, precisa mudar a maneira de atuar; pois, não adianta querer passar muita informação para o educando se ele não estiver entendendo o real significado deste ensinamento para sua vida/realidade. O processo educacional requer do professor conhecimento, afeto, ética e comprometimento com o processo ensino-aprendizagem.

Sendo assim, é importante avaliar o conhecimento prévio dos alunos, auxiliá-los na troca de informações, diálogos, estimular a pesquisa e resgatar valores culturais; e para que todo este processo seja bem-sucedido, o professor deve ter paciência/atenção/afeto/dedicação e levar em conta os elementos fundamentais do processo de aprendizagem.

É dever da escola proporcionar mais diálogo e trocas de experiências; aproveitando o momento para aumentar a autoestima e criar mais vínculos que favorecerão a aceitação da criança ao gerar um convívio mais harmonioso neste universo. Inclusive, o professor deve estreitar o relacionamento entre os alunos para que possa perceber qualquer necessidade que eles tenham, e após, solicitar à equipe pedagógica auxílio para que o psicopedagogo intervenha sempre que necessário.

Nesta abordagem, percebe-se que toda prática pedagógica deve ser dinâmica, flexível e envolvente na transmissão dos conhecimentos. Se isso não ocorrer, o processo educativo tornar-se-á incompleto e desagradável ao educando.

Deve-se ampliar o convívio democrático escolar sendo indispensável a iniciativa e o apoio de toda a família/sociedade em relação aos funcionários; pois equipe unida e que se respeita é capaz de fazer toda a diferença; evoluindo em todos os aspectos; independentemente da situação econômica em que se encontra a escola ou a comunidade. É nesta perspectiva que deve ser organizado 
o trabalho pedagógico; toda a comunidade escolar participando desse movimento dinâmico no cotidiano escolar inclusivo.

Enfim, houve muito avanço em relação à inclusão dos portadores de necessidades especiais nas turmas regulares de ensino, e é fundamental que o termo inclusão seja entendido como sinônimo de emancipação e autonomia. Para tal situação, é fundamental que haja integração entre professores, equipe pedagógica, em especial o orientador educacional e o psicopedagógico; e os demais profissionais, objetivam promover benefícios imensuráveis ao desenvolvimento do corpo discente.

Todas as expectativas oriundas desse engajamento se somam à necessidade constante em estar atento ao aluno especial enquanto indivíduo, dotado de subjetividade e senso comum; e como parte da coletividade, compreendendo suas múltiplas relações e inteligências passíveis de serem estabelecidas no espaço escolar.

\section{CONSIDERAÇÕES FINAIS}

Após todos os detalhamentos aqui delineados, nota-se que o diagnóstico de TEA não é sinônimo de incapacidade de vida, mesmo nos graus mais severos, os estímulos corretos podem proporcionar uma vida digna e ativa no convívio social. Na maioria dos casos, os sintomas autísticos são observados pela escola e repassados à família. A postura da família diante da situação fará toda a diferença.

Outrossim, deve-se pensar as práticas do cotidiano escolar como um horizonte para o surgimento, crescimento e consolidação de um projeto ativamente democrático; como, por exemplo, o Projeto Político Pedagógico e demais projetos interdisciplinares que possam ser desenvolvidos incluindo, inclusive, os familiares e a comunidade escolar em geral.

A complexa relação entre teoria e prática docente, no ambiente de ensinoaprendizado, está atrelada a realidades de inclusão. Tanto os planos de curso quanto os de aula devem se desenvolver a partir da verificação da realidade da linguagem (fática), do perfil discente e de alguma impossibilidade que exija a revisão do conteúdo selecionado. No contexto de alunos especiais, as consequências de ignorar possíveis problemas são considerados graves.

\section{CONGRGÂNAASTEÓRCASDOMNDOCONIEMPORÂNEO}


Portanto, é fundamental que o professor assuma o compromisso de manter as conquistas constitucionais que propõem a elaboração de projetos de inclusão; sendo necessário ir além da sala de aula; além dos conteúdos didáticos tradicionais e conteudistas, e se comprometer com uma construção dialógica e inclusiva.

\section{REFERÊNCIAS BIBLIOGRÁFICAS}

BRASIL. Lei de Diretrizes e Bases da Educação Nacional. Lei n.ํㅗ 9.394 de 20 de dezembro de 1996.

CANDAU, V. M. Reformas educacionais hoje na América Latina. In: MOREIRA, A. F. (Org.) Currículo, políticas e práticas. Campinas, SP: Papirus, p. 2942, 1999.

CHALITA, G. Educação: a solução está no afeto. São Paulo: Editora Gente, 2001.

COSTA. V. A. Políticas de Educação Especial e inclusão no estado do Rio de Janeiro: formação de professores e organização de escola pública. Ci. Huma. e Soc. em Rev., RJ, EDUR, v. 34, n. 12, jan / jun, p. 141-157, 2012.

DECLARAÇÃO MUNDIAL SOBRE EDUCAÇÃO PARA TODOS (Conferência de Jomtien - 1990). Aprovada pela Conferência Mundial sobre Educação para Todos, em Jomtien, Tailândia, de 5 a 9 de março de 1990. Disponível em: https://www.unicef.org/brazil/declaracao-mundial-sobre-educacao-para-todosconferencia-de-jomtien-1990. Acesso em 22 de ago. de 2020.

LUCK, H. A gestão participativa na escola. 6a ed. Rio de Janeiro: Editora Vozes, 2010.

VASCONCELLOS, C. S. Avaliação da Aprendizagem - Práticas de Mudança: por uma práxis transformadora. São Paulo: Libertad, 2003. 